\title{
ANALISIS PENGGUNAAN INTERJEKSI PADA NASKAH DRAMA "PESTA PARA PENCURI" KARYA JEAN ANNOULIH SADURAN RACHMAN SABUR KAJIAN LINGUISTIK
}

\author{
Rahmawati \\ Pendidikan Bahasa Indonesia, Universitas Muhammadiyah Mataram, Indonesia \\ rahmawati123@gmail.com
}

\section{INFO ARTIKEL}

Riwayat Artikel:

Diterima : 21-05-2019

Disetujui : 23-07-2019

Kata Kunci:

Interjeksi; Naskah Drama.

Keywords:

Interjection; Drama script.

\begin{abstract}
ABSTRAK
Abstrak: Ungkapan kata interjeksi tidak mudah dimengerti. Kadang seorang pembaca belum paham apa yang disampaikan oleh pengarang tentang isi novel, sehingga hal ini yang membuat peneliti tentang interjeksi dalam naskah drama dan memberikan pengetahuan tentang apa itu interjeksi. Jadi, interjeksi adalah kata yang digunakan untuk mengungkapkan perasaan seseorang maupun dalam bentuk senang, sedih, kecewa, jijik,marah,kaget,kangen dan sebagainya. Misalkanya, (wah, ngono kuwi, hah, heh, alhamdulillah dan astagfirullahalazim) yang memiliki arti yang berbeda-beda dalam setiap konteks tuturannya.. penelitian ini bertujuan yaitu untuk mengetahui bentuk-bentuk dan fungsi interjeksi yang terdapat dalam naskah drama "pesta para pencuri" karya jean Annoulih Saduran Rachman Sabur. Metode penelitian adalah deskriftif kualitatif dengan metode pengumpulan data yaitu dokumentasi dan telaan, sedangkan metode analisis data adalah identifikasi, klarifikasi, dan interpretasi.Hasil penelitian ini adalah bentuk interjeksi dalam naskah drama "pesta para pencuri" yang sudah ditemukan melalui penelitian sebanyak 9 bentuk interjeksi yaitu: Oh, hah, oh ya, ya, ah, hah,aah,ssst, dan he he he dan ungsi interjeksi ditemukan 7 fungsi interjeksi yaitu: kekecewaan, harapan, kesyukuran, keheranan, kekagetan, panggilan, dan marah atau makian.
\end{abstract}

Abstract : The expression interjection is not easy to understand. Sometimes a reader does not understand what is conveyed by the author about the contents of the novel, so this is what makes researchers about the interjection in the play an provide knowledge about what is interjection. So, interjection is a word used to express someone's feelings and in the form of happy, sad, disappointed, disgusted, angry, shocked, missed, and so on. For example, (Wow, Ngono Kuwi, Hah, Heh, Alhamdulillah and Astagfirullahalazim) which have different meanings in each context of the speech. This research aims to find out the formsand functions of the interjection contained in the drama script "party of thieves". The work Jean Annoulih Saduran Rachman Sabur. The research method is qualitative descriptive with data collection methods, namely documentation and research, while the data analysis method is indentification, clarification, and interpretation. The result of this study are forms of interjection in the drama script "party of thieves" which have been found through research as many as 9 forms of interjection, Oh, Hah, Oh yes, Yes, Ah, Hah, Aah, Stt, and He he he and interjection function found 7 interjection functions , namely: disappointment, hope, gratitude, astonishment, shock, call, and anger or curse.

\section{A. LATAR BELAKANG}

Bahasa merupakan sarana penting bagi aspek kehidupan bermasyarakat. Sebagai saramna berkomunikasi bagi manusia, penggunaan bahasa yang baik akan memudahkan seseorang dalam menyampaikan ide, gagasan, maupun pemikiran, sehingga dapat dimengerti oleh lawan bicara.bahasa 
juga menjadi pencitraan suatu bangsa. Kebudayaan dapat dibentuk dan dikembangkan melalui bahasa. Di dunia terdapat bermacam-macam bahasa yang merupakan identitas suatu bangsa. Keberanekaragaman bahasa itu memiliki aturan dan keunikannya tersendiri.

Kegiatan berbahasa tidak bisa lepas dari kehidupan manusia. Bahasa adalah suatu hal yang sangat penting dalam kehidupan sehari-hari, karena dengan bahasa kita dapat berkomunikasi dengan orang lain dan berguna untuk saling berhubungan satu dengan yang lainnya. Hakikat manusia sebagai makhluk sosial mengharuskan manusia untuk berinteraksi dengan sesama. Interaksi bisa terwujud dengan adanya bahasa sehingga muncul kegiatan yang dinamakan komunikasi. Dalam setiap komunikasi, manusia saling menyampaikan informasi yang ada berupa pikiran, gagasan, maksud, perasaan, maupun emosi secara langsung (Chaer,2011:47)

Karya sastra merupakan salah satubentuk seni dcengan menggunakan media massa. Karya sastra tercipta melalui perenungan yang mendalam dengan tujuan untuk dinikmati, dipahami oleh masyarakat. Salah satu bentuk karya sastra itu adalah novel. Novel yang digunakan dalam penelitian ini menggunakan novel karya suparto brata yang berjudul 't spookhuis (Gedhong Setan) yang menceritakan tentang Totje seorang anak pribumi yang bersekolah di HBS sekolah Belanda. Komunikasi dalam sebuah karya sastra sangatlah penting digunakan untuk menyampaikan ide, gagasan, pesan, dan ungkapan pikiran yang akan penulis sampaikan kepada pembaca. Dalam karya sastra, terkadang penulis ingin menyampaikan tentang isi dari sebuah karya sastra. Ada beberapa hal yang ingin disampaikan penulis menggunakan sebuah ungkapan atau pesan yang menggunakan perasaan yang sering disebut dengan interjeksi.

Ungkapan perasaan yang disebut interjeksi dapat ditemukan dalam naskah drama. Wedhawati (2006, 417-418) menjelaskan bahwa interjeksi merupakan kategori kata yang ada untuk mengungkapkan rasa hati penuturnya. Interjeksi dibedakan menjadi dua bentuk yaitu interjeksi bentuk primer dan interjeksi bentuk sekunder. Penggunaan interjeksi tidak hanya digunakan dalam komunikasi langsung melainkan komunikasi tulis. Ada beberapa hal yang ingin disampaikan penutur kepada mitra tutur atau kepada orang lain seperti: kebahagiaan, kesedihan, kekaguman, terkejut, rasa marah, rasa kasihan, ketakutan, atau bentuk ejekan. Kata tersebut disebut dengan interjeksi. Menurut Mulyana (2011:77) kata seru yaitu kata yang dipakai untuk menyatakan atau melahirkan rasa. Interjeksi dapat diartikan sebagai kata atau ujaran yang bertujuan untuk mengungapkan perasaan ataupun isi hati seseorang dimana kata yang mengungkapkan perasaan batin. Ungkapan kata injeksi tidak mudah dimengerti. Kadang seorang pembaca belum apa yang disampaikan pengarang tentang isi novel, sehingga hal ini yang membuat peneliti tertarik untuk meneliti tentang interjeksi dalam naskah drama dan memberikan pengetahuan tentang apa itu interjeksi. Jadi, interjeksi adalah kata yang digunakan untuk mengungkapkan perasaan seseorang maupun dalam bentuk senang, sedih, kecewa, jijik, marah, kaget, kangen, dan sebagainya. Misalnya, (wah, ngeno kuwi, hah, heh, Alhamdulillah dan astagfirullahalazim) yang memiliki arti yang berbeda-beda dalam setiap konteks tuturannya.

\section{B. METODE PENELITIAN}

Penelitian ini adalah deskriptif kualitatif, yaitu penelitian yang bermaksud untuk memahami penomena tentang apa yang dialami subjek penelitian. Misalnya perilaku, persepsi, motivasi, tindakan, dan lain-lain secara holistic, dan dengan cara deskripsi dalam bentuk kata-kata dan bahasa, pada suatu konteks khusus yang alamiah dan dengan memamfaatkan berbagai metode alamiah (Moleong, 2012:6) Metode deskriptif dapat diartikan sebagai prosedur pemecahan masalah dengan menggambarkan atau melukiskan keadaan subjek atau objek penelitian (seseorang, lembaga, masyarakat dan lain-lain) pada saat sekarang berdasarkan fakta-fakta yang tampak atau sebagaimana yang ada, (siswantoro, 2005:56)

Objek penelitian ini adalah analisis penggunaan interjeksi yang terdapat dalam naskah drama pesta para pencuri. Penelitian ini merupakan penelitian kajian pustaka.

Data dalam penelitian ini adalah Nilai kemanusiaan yang terdapat dalam naskah pesta para pencuri. Data pada hakikatnya adalah segala sesuatu yang sudah dicatat (recorded) segala sesuatu itu bisa berbentuk dokumen, batu, air, pohon, manusia, dan 
sebagainya. (mahsun, 2005: 16). Data dalam penelitian ini diambil dari hasil transliterasi dan terjemahan naskah pesta para pencuri. Transliterasi dan terjemahan naskah ini sendiri terdiri terdiri dari 40 halaman dengan teks 898 .

Menurut Lofland dalam (Moloeng,2012:157) sumber data utama dalam penelitian kualitatif ialah kata-kata, dan tindakan, selebihnya adalah dua tambahan seperti dokumen dan lain-lain. Adapun yang menjadi sumber data adalah pesta para pencuri karya jean annoulih saduran ranchman sabur.

\section{HASIL DAN PEMBAHASAN}

\section{Sinopsis Naskah Drama Pesta Para Pencuri}

Naskah ini menceritakan kehidupan tiga orang pencuri yang bertemu dengan seorang nyonya kaya raya, ia memiliki dua orang keponakan singkat kenalan dengan nyonya dan keponakannya. Akhirnya ketiga pencuri ini berusaha mengajak mereka berkencan dengan tujuan agar mereka bisa berpacaran lalu dengan mudah leluasa menguasai harta nyonya dan kedua keponakannya, tapi ternyata nyonya yang mereka intai hartanya itu juga seorang pencuri.Lakon dimulai dengan kejadian nyonya marah besar karena da yang mencuri barang wasiat miliknya yang sangat berharga. Situasi memang sudah tidak nyaman lagi karena banyak pencuri yang berkeliaran. Para pencuri itu dengan pintar dan lihaimenyamar menjadi apa saja, sehingga sulit dikenali. Ada dua pencuri yang dikenal sebagai "pencuri baik hati dan suka menolong rakyat". Keduanya merasa terganggu karena nama baiknya dicemarkan oleh berbagai cara pencurian yang disebutnya tidak bertanggung jawab dan tidak menjunjung tinggi martabat pencuri. Sementara gerombolan pencuri lainnya ingin membuktikan bahwa mereka adalah pencuri yang bisa dipercaya.

Tetapi nyonya mencurigai bahwa situasi yang penuh kecurigaan ini sengaja dikondisikan oleh penjaga keamanan wilayah. Penjaga keamanan ada dua orang yang dikenal sebagai pencuri yang telah sadar kecurigaan Nyonya. Ketika keadaan menjadi tertib dan baik, dua petugas keamanan itu seperti kehilangan peran, karenanya dengan sengaja membuat situasi menjadi tidak aman,agar mereka bisa kembali dibutuhkan.

Banyak para pencuri yang menyukai anak Nyai Salma. Mereka memperebutkan cinta anak Nyai Salma. Karena para pencuri itu saling mengakali dfan menebar berita hoax. Ditengah situasi seperti itu, pembantu kepercayaan Nyonya, mulai mencium gelagat buruk, terutama ketika para pencuri ini berkumpul dan bersepakat untuk melakukan gerakan pencurian besar-besaran.

Para pencuri itu mulai sering mencuri. Sampai akhirnya mereka menyadari bahwa diam-diam mereka tengah dicuri oleh seorang Pencuri Agung yang selama ini namanya menjadi legenda dalam dunia para pencuri, tetapi tak mereka kenali siapa gerangan sesungguhnya.

\section{Bentuk-bentuk Interjeksi Yang Terdapat Dalam Naskah Drama "Pesta Para Pencuri" Karya Jean Annoulih Saduran Ranchman Sabur}

Berdasarkan masalah yang terdapat dalam penelitian ini, pembahasan pada bab ini dibagi menjadi dua bagian. Pembahasan tersebut meliputi bentuk interjeksi, dan fungsi interjeksi dalam teks naskah drama, ditemukan bentuk sederhana dan bentuk turunan.

Bentuk sederhana terdiri dari interjeksi asli dan interjeksi yang berasal dari kata lain dalam teks naskah drama. Bentuk turunan terdiri dari reduplikasi dan gabungan kata. Interjeksi asli yang dimaksud adalah kata yang dihasilkan dari ujaran atau seruan dalam teks naskah drama. Interjeksi asli teks naskah drama memperlihatkan bentuk yang sederhana. Interjeksi ini merupakan bentuk asli dari teks naskah drama. Interjeksi ini juga tidak terdapat pada kamus bahasa Indonesia interjeksi bentuk asli disertai dengan kalimat untuk memperjelasnya. Satu diantara kalimat dari interjeksi tersebut

Tabel 1. Interjeksi Menurut Bentuknya

\begin{tabular}{|l|c|l|}
\hline No & \multicolumn{1}{|c|}{ Deskripsi } & \multicolumn{1}{c|}{ contoh } \\
\hline 1 & $\begin{array}{l}\text { Interjeksi sederhana } \\
\text { (simple interjections) }\end{array}$ & $\begin{array}{l}\text { Oh, Hah, Oh ya, Ya, } \\
\text { Ah, Aaah,Ssst, he he } \\
\text { he, Hah, tidak, he }\end{array}$ \\
\hline 2 & $\begin{array}{l}\text { Interjeksi turunan } \\
\text { (derived interjection) }\end{array}$ & $\begin{array}{l}\text { Mengerikan, } \\
\text { sayang sekali, } \\
\text { baiklah, ya tuhan, } \\
\text { masa, demi tuhan, } \\
\text { Hello, Diam, gila, } \\
\text { bodoh. }\end{array}$ \\
\hline
\end{tabular}




\section{SIMPULAN DAN SARAN}

Bentuk interjeksi dalam naskah drama "pesta para pencuri" yang sudah ditemukan melalui penelitian inisebanyak 9 bentuk injeksi yaitu Oh, hah, oh ya, ya, ah, hah,aah,ssst, dan he he he. Masingmasing bentuk memiliki ungkapan yang berbeda yang digunakan dalam naskah drama "pesta para penari"

Fungsi interjeksi ditemukan 7 fungsi interjeksi yaitu kekecewaan, harapan, kesyukuran, keheranan, kekagetan, panggilan, dan marah atau makian. Interjeksi yang paling banyak digunakan adalah berntuk marahatau makian. Hal ini menunjukkan bahwa pengarang banyak memilih interjeksi bentuk marah atau makian sebagai bagian untuk menyampaikan sesuatu yang perasaan marah si tokoh. Interjeksi yang paling sedikit digunakan adalah bentuk keheranan yaitu kata hah yaitu sebagai 1 kata. Dengan demikian bentuk keheranan merupakan pilihan yang paling sedikit digunakan pengarang dalam menyampaikan suatu perasaan si tokoh.

Kepada para peneliti lain disarankan agara hasil penelitian ini dapat dimamfaatkan sebagai acuan. Acuan dalam melakukan penelitian yang lebih mendalam mengenai Naskah Drama "Pesta Para Pencuri"

Disarankan kepada pembaca agar hasil dalam penelitian dapat dijadikan wawasan dan ilmu pengetahuan.

\section{REFERENSI}

Abdurrahman Fathoni. 2006. Metodelogi penelitian dan teknik penyusunan skripsi. Jakarta: PT Rineka Cipta

Anonim. 2015. Kamus besar bahasa Indonesia. Online.kbbi web.id. diakses pada tanggal 5 januari, pukul 4.42 wib. Yogyakarta

Arikunto, S.,2007, Prosedur Penelitian Suatu pendekatan Praktek Edisi Revisi VI hal 134, Rineka Apta, Jakarta.

B.S., Kusno. 1986.pengantar tata bahasa Indonesia. Bandung. CV Rosda.

Chaer,Abdul. 2003. Tata Bahasa praktis Bahasa Indonesia. Jakarta: Rineka Cipta.

Hasanuddin.1996. Drama, Karya Dalam Dua Dimensi Kajian Teori, Sejarah, dan Analisis. Bandung:Angkasa.

Ida Bagus, Putrayasa. 2007 Analisis kalimat : fungsi, kategori, dan peran, Bandung: Refika Aditama.
Kridalaksana, Harimuri. 2007. Kelas kata dalam bahasa Indonesia. Jakarta: Gramedia utama pustaka Lombok: cerdas press

Kusno, B.S. 1986. Pengantar Tata Bahasa Indonesia. Bandung.

Luxemburg, Jan Van dkk. 1984. Pengantar ilmu sastra (Terjemahan Dick Hartoko). Jakarta:Gramedia 